\title{
Experimental Study on the Influence of Driving Speed of Railway Passenger Train on Fire Combustion Characteristics
}

\author{
Jing Xuan Wang ${ }^{1}$ a, Wan Fu Liu ${ }^{1}$, Wei Ping Han², Jian Jun Xia² and Ya Liu \\ ${ }^{1}$ School of Mechanical Engineering, Tianjin University of Commerce, Tianjin 300134, China \\ ${ }^{2}$ Tianjin Fire Research Institute of MPS, Tianjin 300381, China \\ a790814353@qq.com
}

\begin{abstract}
Keywords: railway passenger train, driving speed, heat release rate.
Abstract. With the rapid development of the railway passenger train in China, the safety of train operation has become the focus of attention. The railway passenger train due to narrow and limited space, more combustibles within the compartment and the passengers are highly concentrated, in the event of a fire accident, it often cause catastrophic consequences. According to the principle of relative motion, the change of wind fan frequency is used to change the wind speed to replace the train speed, so as to study on the fire combustion characteristics when the railway passenger train runs at different speed. The research results showed that: When the train fire and part of the windows was ruptured, the maximum fire heat release rate and the fire growth rate increases with the increase of train speed, and time to reach the peak is gradually reduced.
\end{abstract}

\section{Introduction}

The accelerated development of urbanization has promoted the demand for safe and convenient transportation system. The development of high-speed railway in China has also made remarkable achievements. The railway passenger compartment environment is relatively closed, have combustible materials and highly intensive personnel, once the fire accident, it will lead to disastrous consequences $[1,2]$. When the fire occurs in a tunnel, the driver cannot stop it because of the poor control performance of the vehicle; or the rear end of the locomotive is on fire, the driver will continue to operate without knowing it, which will form a fire source inside the tunnel. If the train carries fire source and lasts longer, it will cause crashing phenomenon directly [3]. It can make the fire spread faster, extremely adverse to the personnel evacuation and fire [4].Therefore, it is great of practical significance to study the combustion characteristics of the train during the operation of the tunnel fire rescue and personnel escape.

\section{Description of the Experiment}

\section{Experiment Facilities}

At present, there are two methods for research the tunnel fire: experimental research and numerical simulation. This experiment based on the similarity principle, according to the differential control equation of smoke flow in the tunnel fire, the similarity criterion of the model test is derived by the similarity transformation method. It is obtained that the Froude fire model with the similarity scale of 1:4[5]. The schematic diagram of the measurement principle is in Fig.1.

The experiment was carried out in the model tunnel with the scale ratio of 1:4 and the model size is $86 \mathrm{~m} * 3.3 \mathrm{~m} * 1.8 \mathrm{~m}$. According to the principle of relative motion, the speed of the railway passenger train in the tunnel is replaced by the air flow in the cross section of the tunnel. Through the tunnel fan provide section wind speed simulation of train speed. The train model is placed in the stable section of the wind speed in the tunnel. The experiment used the train prototype for $25 \mathrm{~T}$. According to reduced scale of $1: 4$, the size of the train model is $6.65 \mathrm{~m}^{*} 0.78 \mathrm{~m}^{*} 1.1 \mathrm{~m}$. 


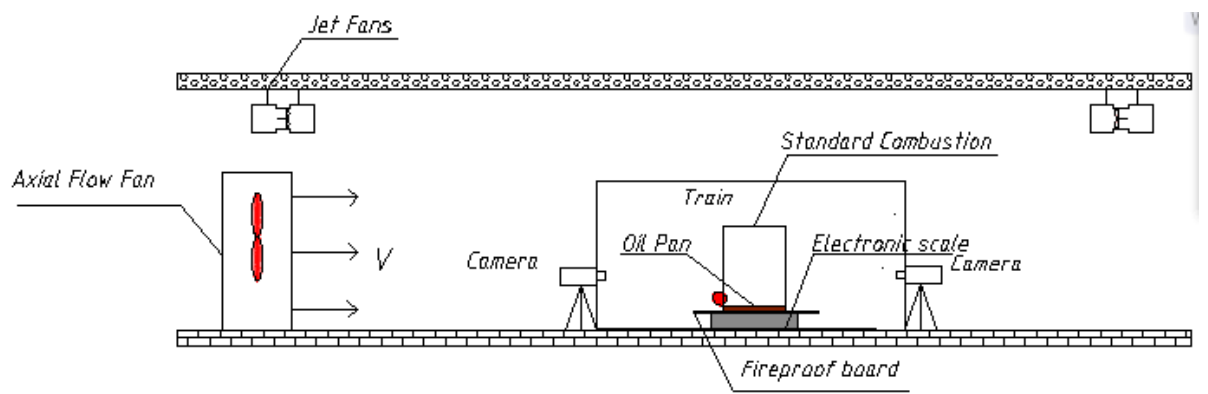

Fig.1 Schematic diagram of measurement principle

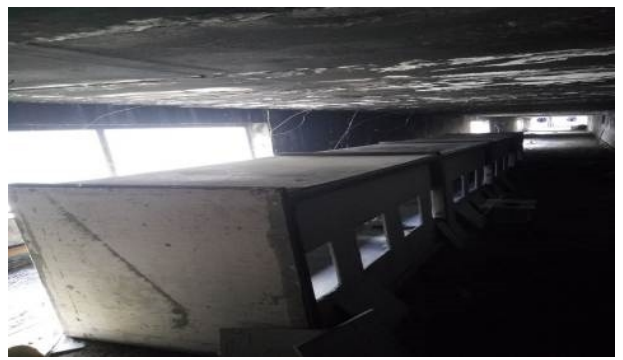

Fig.2 Entity of railway passenger train

\section{Setting Fire Source}

In order to improve combustion stability, using standard combustion material as fuel [6]. The standard combustion materials are paper cups and corrugated case, in which the size of the corrugated case is $500 \mathrm{~mm} * 500 \mathrm{~mm} * 500 \mathrm{~mm}$. The paper cup is made of whole wood pulp. The train carriage was placed in the central position inside the combustion compartment, it adopts a single angle ignition measure.

\section{Experimental Measurement Method}

Principle of Heat Release Rate Measurement. Heat release rate [7] refers to the amount of heat released by fuel combustion in unit time. It is one of the main parameters characterizing fire risk. There are three methods to determine the heat release rate of fire source: Heat loss method, Oxygen consumption method and Radiation method. At present, the heat release rates of fire source are mainly determined by three methods: thermal gravimetric method, the oxygen consumption method and radiation method. In this experiment, the heat release rate is measured by the thermal gravimetric method. The mass change of fuel combustion is measured by electronic scale, and the change law of mass with time is obtained.

$$
Q_{f}=\chi \dot{m} \sum \Delta H
$$

For the thermal gravimetric method, formulae of the thermal gravimetric method are detailed as follows Eq.1, which the $\mathrm{Q}_{\mathrm{f}}$ is the heat release rate, the $\chi$ is the combustion efficiency, the $\Delta H$ is the heat value on fuel and the $\dot{m}$ is the mass loss rate.

Principle of Temperature Measurement System. In order to conveniently observe the temperature variation in the compartment during the fire, five thermocouples are arranged on the top of the railway passenger train. The schematic diagram of temperature measurement points are shown in Fig.3.

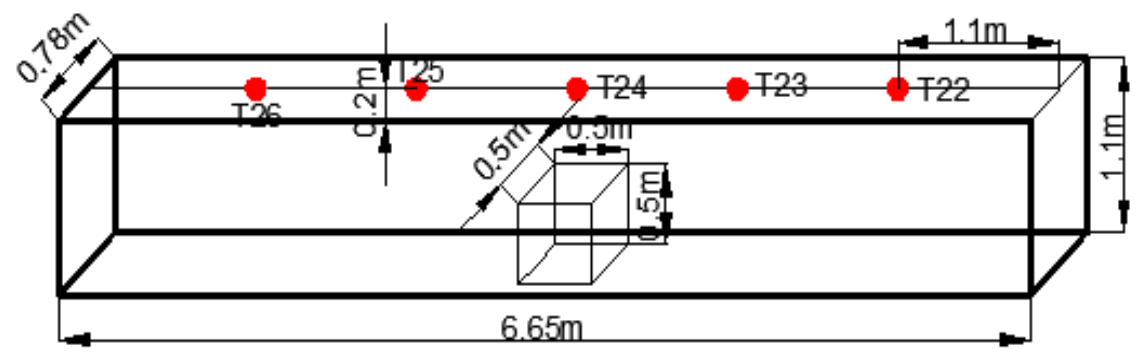

Fig.3 Schematic diagram of temperature measurement points for the railway passenger train 


\section{Determination of Experimental Conditions}

According to the investigation, the running speed of the railway passenger train is $160 \mathrm{~km} / \mathrm{h}$, during the braking process, the average braking speed is $80 \mathrm{~km} / \mathrm{h}$. When the railway passenger train was on fire in the tunnel, due to its narrow semi-closed space, it should be out of the tunnel or driving to the tunnel emergency station for evacuation and fire extinguishing, to prevent the large amount of heat released when a fire and poisonous gas against, seriously affect the evacuation [8]. When a railway passenger train on fire and the ventilation rate was enough to support combustion, flashover was easy to occur. It may lead to the rupture of the window [9]. The experiment purpose is to investigate the fire Combustion characteristics when the railway passenger train runs at different speeds. This paper discusses the distribution law of the fire heat release rate and temperature. Because of the window rupture occurs near the fire source, it is considered that the four windows symmetrically distributed around the fire source are broken.

Table 1 Experimental conditions for railway passenger train

\begin{tabular}{cccc}
\hline Condition & $\begin{array}{c}\text { Simulated wind speed } \\
{[\mathrm{m} / \mathrm{s}]}\end{array}$ & $\begin{array}{c}\text { Equivalent speed } \\
{[\mathrm{km} / \mathrm{h}]}\end{array}$ & $\begin{array}{c}\text { Combustion weight } \\
{[\mathrm{kg}]}\end{array}$ \\
\hline No windows was ruptured & - & - & 4.20 \\
& 8.89 & 80 & 4.35 \\
Part of the windows was ruptured & 11.11 & 100 & 4.35 \\
& 15.55 & 140 & 4.30 \\
\hline
\end{tabular}

\section{Analysis}

\section{Effect on Heat Release Rate}

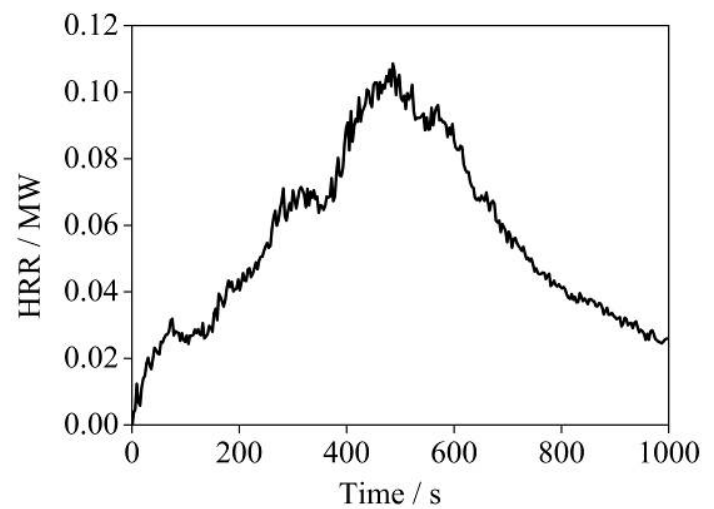

Fig.4 The curve of fire heat release rate with time in case of no window burst

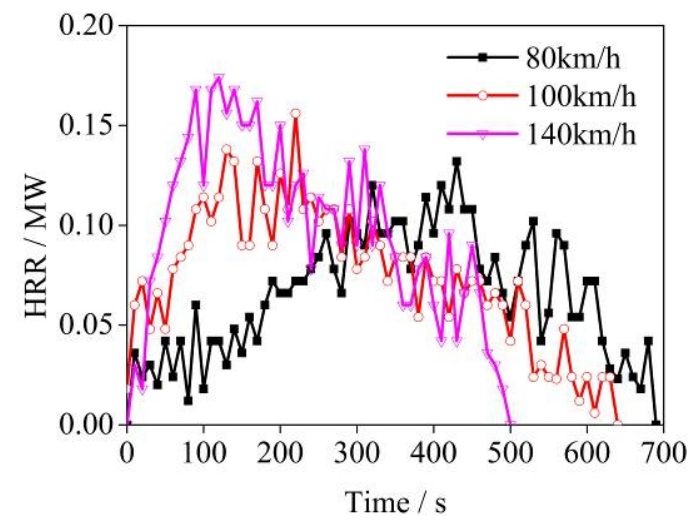

Fig.6 Heat release rate curve of train running at different speeds under partial window rupture

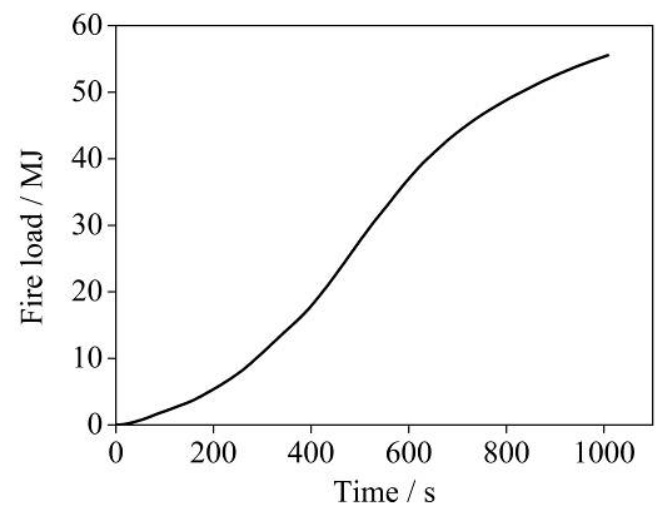

Fig.5 The curve of fire load with time in case of no window burst

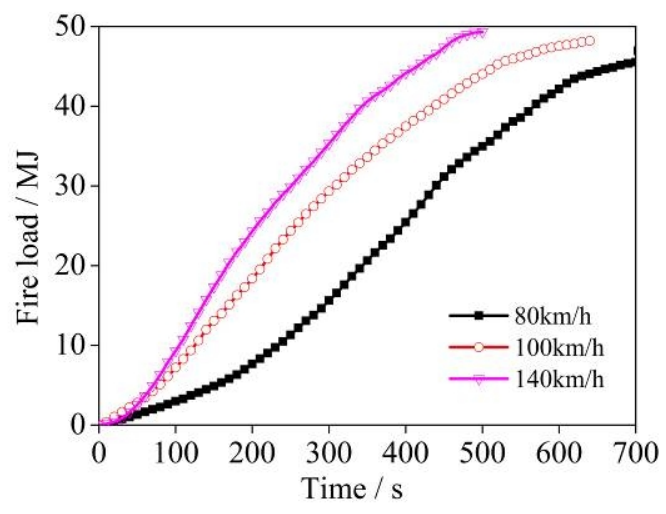

Fig.7 Fire load curve of train running at different speeds under partial window rupture 
From Fig.4 to Fig.7, The results show that the trend of the heat release rate curve is basically the same regardless of whether the window was broken or not, showing a single peak distribution. During combustion, the fire heat release rate showed first increases and then decreased. The fire growth period shows gradually accelerated state, and the fire attenuation period shows gradually decelerate state. When some windows were ruptured, the peak of the fire heat release rate is increasing with the running speed of the railway passenger train, and the time to reach the peak is gradually reduced. The combustion time also decreases with the increase of train speed. This is because some windows were broken, then the air velocity on the railway passenger train increases with the increase of the train speed, which makes the mixture of combustion and oxygen fully mixed, so the combustion is more and more intense. The statistical table of fire heat release rate data is shown in Table 2.

Table 2 The statistical table of fire heat release rate data

\begin{tabular}{cccccc}
\hline Condition & $\begin{array}{c}\text { Speed } \\
{[\mathrm{km} / \mathrm{h}]}\end{array}$ & $\begin{array}{c}\text { Maximum of } \\
\text { HRR[kW] }\end{array}$ & $\begin{array}{c}\text { The time of } \\
\text { HRR peak[s] }\end{array}$ & $\begin{array}{c}\text { Theoretical fire } \\
\text { load[MJ] }\end{array}$ & $\begin{array}{c}\text { Fire } \\
\text { Load[MJ] }\end{array}$ \\
\hline No windows was & - & 108.5 & 486 & 63.00 & 55.30 \\
ruptured & - & & & & 65.25 \\
Part of the windows & 80 & 132 & 430 & 65.52 \\
was ruptured & 100 & 156 & 220 & 64.50 & 48.20 \\
\hline
\end{tabular}

Effect on the Growth Rate of Fire Rise

The fire growth rate is an important index to measure the fire risk. It is mainly used to describe the speed of fire development. This experiment used $t^{2}$ fire model. According to the experimental results, the growth rate of each heat release rate curve was fitted respectively, and the fire growth rate was obtained.

Table 3 The statistical table of the growth rate of fire rise

\begin{tabular}{ccc}
\hline Condition & $\begin{array}{c}\text { Speed } \\
{[\mathrm{km} / \mathrm{h}]}\end{array}$ & $\begin{array}{c}\text { The fire growth rate } \\
{\left[\mathrm{kW} / \mathrm{s}^{2}\right]}\end{array}$ \\
\hline No windows was ruptured & - & 0.000459 \\
& 80 & 0.000714 \\
Part of the windows was ruptured & 100 & 0.003223 \\
& 140 & 0.012
\end{tabular}

Table 3 shows that the fire growth rate is not related to the speed of the train, when the train window was not ruptured. When the part of the windows were ruptured and the train speeds were $80 \mathrm{~km} / \mathrm{h}, 100 \mathrm{~km} / \mathrm{h}$, the fire growth rate belongs to slow fire $\left(\alpha=0.00277 \mathrm{~kW} / \mathrm{s}^{2}\right)$. While the train speed was $140 \mathrm{~km} / \mathrm{h}$, the fire growth rate belongs to medium speed fire $\left(\alpha=0.01172 \mathrm{~kW} / \mathrm{s}^{2}\right)$. That is to say, the fire growth rate increases with the train running speed up. Reducing the running speed will reduce the fire growth rate.

\section{Effect on the Temperature at the Top of the Train}

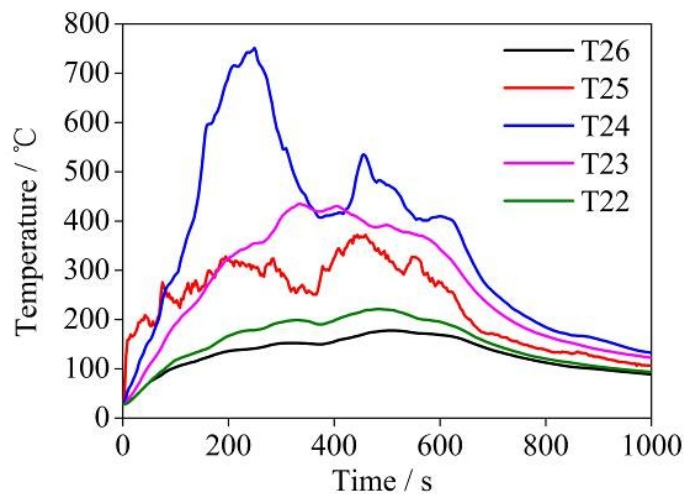

Fig. 8 The curve of ceiling temperature in the train running without window rupture

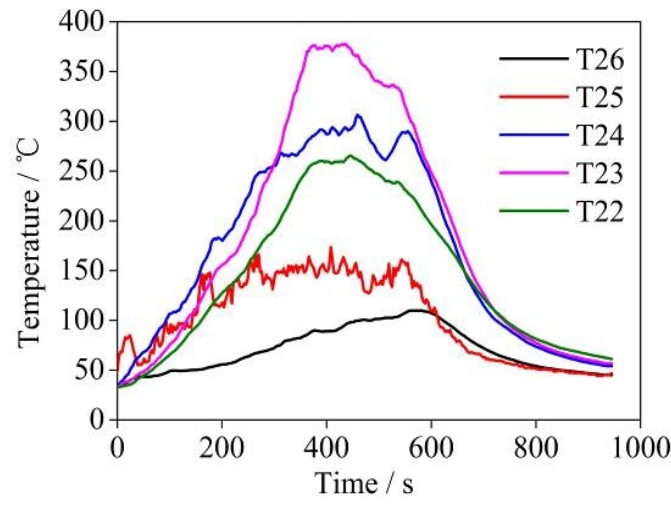

Fig.9 The curve of ceiling temperature in the train at the speeds of $80 \mathrm{~km} / \mathrm{h}$ under partial window rupture 


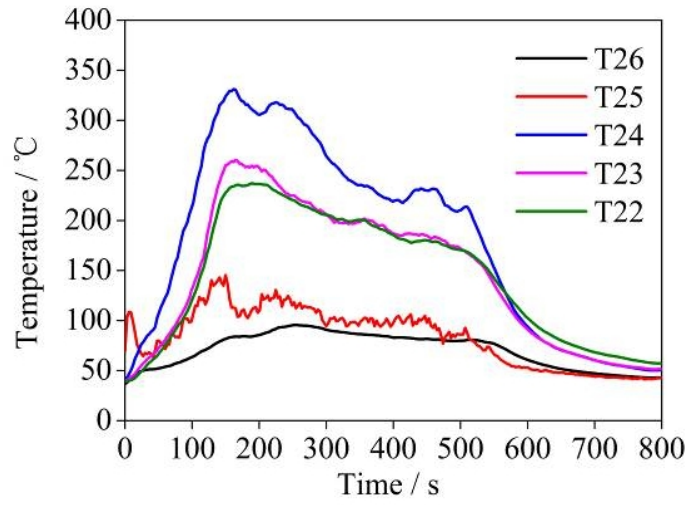

Fig.10 The curve of ceiling temperature in the train at the speeds of $100 \mathrm{~km} / \mathrm{h}$ under partial window rupture

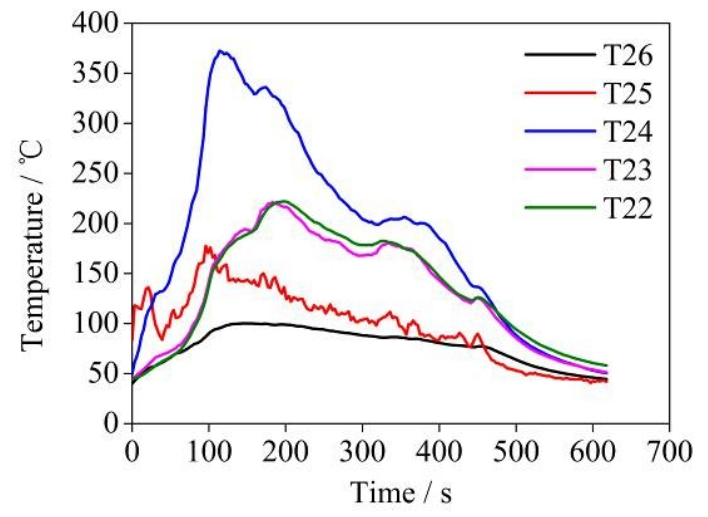

Fig.11 The curve of ceiling temperature in the train at the speeds of $140 \mathrm{~km} / \mathrm{h}$ under partial window rupture

From Fig. 8 to Fig.11 shows that the highest temperature is at the top of the combustion source in the absence of a broken window, this is because the train belongs to the closed space, which is not affected by external factors, so the combustion without deflection. When some windows were ruptured, the train ceiling temperature gradually to the two sides of the carriage are decreasing, which is due to the influence of ceiling jet, smoke gradually spread to the sides. The flue gas heat exchange with the cold air, so the energy is reduced, the temperature also gradually reduced.

In addition, when some windows were ruptured and run at different speed, with the increase of train speed, the extreme temperature of the top of the train has little change, but where all appear above the fire source. At a distance of $1.1 \mathrm{~m}$ from the combustion source, the temperature decreases with the increase of train speed, this is because with the increase of train speed, the intake of the air also increases, so the temperature will be decreased. And the combustion time also decreases with the increase of running speed.

Whether the windows were ruptured or not, compared with the temperature variation, the results show that the maximum temperature of the train ceiling is gradually decreased with the window ruptured. This is due to the rupture of the window, improving the heat dissipation capacity, so the train ceiling temperature will drop. The temperature extreme points of the railway passenger train ceiling are shown in Table 4.

Table 4 Temperature extreme points of railway passenger train ceiling

\begin{tabular}{ccccc}
\hline Condition & $\begin{array}{c}\text { Speed } \\
{[\mathrm{km} / \mathrm{h}]}\end{array}$ & $\begin{array}{c}\text { Temperature extreme } \\
\text { point }\left[{ }^{\circ} \mathrm{C}\right]\end{array}$ & $\begin{array}{c}\text { The time of } \\
\text { Temperature peak[s] }]\end{array}$ & $\begin{array}{c}\text { Burning } \\
\text { time[s] }\end{array}$ \\
\hline $\begin{array}{c}\text { No windows was } \\
\text { ruptured }\end{array}$ & - & 751.0 & 249 & 993 \\
Part of the windows & 80 & 377.2 & 438 & 942 \\
was ruptured & 100 & 331.2 & 162 & 789 \\
& 140 & 372.4 & 114 & 609 \\
\hline
\end{tabular}

\section{Conclusions}

(1) Whether the window was ruptured or not, the overall change trend of the heat release rate curve is basically identical, showing a single peak distribution. In the case of no window rupture, the fire heat release rate, fire growth coefficient and train ceiling temperature extremes are not affect by the train speed.

(2) When some windows are ruptured and driving at different speeds, the temperature of the extreme point of the roof of the train was little different, but the maximum temperature at the top of the train decreased gradually with the rupture of some windows. Under different operating conditions in the same position, the temperature decreases with the train speed improvement. The peak value of 
heat release rate increases with the increase of train running speed, while the time to reach the peak is gradually reduced, and the combustion time is shortened.

(3) When a railway passenger train fires in a tunnel and some windows have ruptured, the growth rate of the fire increases with the train speed up, while the fire scale increases first and then decreases. Therefore, after the railway passenger train caught fire, in order to ensure the safety, the running speed should be appropriately reduced.

\section{Acknowledgements}

This work was financially supported by National Science and Technology Support Program of "The 12th Five-Year" Plan Period, Program (2014BAK17B02), National Science and Technology Support Program of "The 12th Five-Year" Plan Period, Program (2014BAK17B03).

\section{References}

[1] Tao W. Review of Research on Fire Prevention of Traffic Tunnel. China Public Security (2010).

[2] Peacock R D, Averill J D, Madrzykowski D, et al. Fire Safety of Passenger Trains; Phase III: Evaluation of Fire Hazard Analysis Using Full-Scale Passenger Rail Car Tests(2004).

[3] Zong R W. Fire Reconstruction Research of Flashover in the Special Confined. University of Science and Technology of China (2008).

[4] Lattimer B, Beyler C. Heat Release Rates Of Fully-developed Fires In Railcars. Fire Safety Science. 2005, 8:1169-1180.

[5] Lee S R, Hong S R. A numerical study on smoke movement in longitudinal ventilation tunnel fires for different aspect ratio. Building \& Environment. 2006, 41(6):719-725.

[6] Lin X, Yu D X, Zhang J. Combustion Characteristics and Influencing Factors of Standard Combustion Materials for Fire Test. Fire Science and Technology. 2014, 33(1):10-13.

[7] Kong, D., N. Johansson, P. van Hees, S. Lu, and S. Lo. "A Monte Carlo analysis of the effect of heat release rate uncertainty on available safe egress time", Journal of Fire Protection Engineering (2012).

[8] Xi Y H, Mao J. Effects of Moving Speed of On-Fire Subway Train on Heat Release Rate. Journal of South China University of Technology. 2016, 44(4):123-129.

[9] Lee D H, Park W H, Hwang J, et al. Full-Scale Fire Test of an Intercity Train Car. Fire Technology. 2016, 52(5):1559-1574. 